Technical Note:

\title{
Datalogger control of environmental chambers for variable-temperature germination experiments
}

\author{
STUART P. HARDEGREE AND MICHAEL D. BURGESS
}

\begin{abstract}
Authors are plant physiologist and electronics technician, USDA-ARS, Northwest Watershed Research Center, 800 Park Blvd., Plaza IV, Suite 105, Boise, Ida. 83712.
\end{abstract}

\begin{abstract}
Environmental conditions in the seedbed are much more variable than have historically been simulated in laboratory germination experiments. This paper describes a laboratory control system for real-time simulation of seedbed temperature regimes. The system is composed of a set of small refrigerators that have been enhanced with incandescent and fluorescent lights, fans and electrical-resistance heaters. The germination chambers are regulated by an electronic data acquisition/control system that allows each chamber to vary internal temperature on a continuous basis. Field temperatures can be transmitted to the laborato$r y$ and the germination chambers programmed in near-real-time for simultaneous laboratory germination/field emergence studies.
\end{abstract}

Key Words: field variability, environmental control, seed response

Rangeland ecosystems are characterized by a high degree of spatial and temporal variability in seedbed microclimate (Pierson and Wight 1991). Most information regarding environmental control of seed germination, however, comes from laboratory experiments using constant and alternating-constant temperature regimes that do not necessarily reflect natural seedbed conditions (Wester 1991). Field studies to evaluate variable-temperature response are confounded by complex combinations of microclimatic variables that make it difficult to separate temperature effects and to replicate temperature treatments (Hurlbert 1984). Our ability to predict and understand field germination would be enhanced if we could better simulate variable environmental scenarios under controlled and replicable conditions in the laboratory. The purpose of this paper is to describe the development and evaluation of a programmable control system for simulating variable-temperature regimes for seed germination studies. The spccific objective was to develop a system that would allow for labo-

Research was funded in part by the Bureau of Land Management, Intermountain Greenstripping and Rehabilitation Research Project, under interagency agreement USDI/BLM 60-91H2-8-0020.

Mention of a trademark name or proprietary product does not constitute endorsement by the USDA and does not imply its approval to the exclusion of other products that may also be suitable.

Manuscript accepted 17 Feb. 1995. ratory simulation of near-real-time field conditions for concurrent laboratory germination/field emergence studies.

\section{Materials and Methods}

\section{System Design and Control Features}

Individual control chambers consisted of a standard $0.17-\mathrm{m}^{3}$ refrigerator that had been stripped of internal shelving. Molded shelving was also removed from the door and replaced with a flat plastic sheet that fit flush with the plane of the door. The compressor cooling coil of these refrigerators was contained within a thin panel that covered the entire back wall of the chamber. The interior of the chamber was fitted with 4 sets of aluminum support rods to create equally spaced shelves that each held up to 4 trays of germination vials. Each tray was designed to hold 7 germination vials of the type described by Hardegree and Emmerich (1992) for water potential control in seed germination studies. Eight incandescent light strips, each with a 7 Watt power output, were affixed to the sides of the chamber, 1 each on the right and left sides of the 4 shelves. A single 15 Watt fluorescent light strip was affixed to the center of the back wall and spanned all shelf levels. The lighting circuit contained a manual switch to control the lights to be either all on, incandescent only, or fluorescent only. The incandescent lights were also switch selectable to either full or half power. Two small wire-wound resistance heaters were affixed to the upper corners of the rear wall to provide heating of the unit when the lights were off. These provided approximately 50 Watts of heat when connected to a 110 volt $\mathrm{AC}$ power source. Five small fans were installed to circulate air and minimize temperature gradients within the chamber. Three of the fans were attached to the bottom panel of the chamber and 1 was placed immediately next to each heating unit.

A Campbell Scientific CR10 datalogger was used to monitor temperature and to control photoperiod, heating, and cooling. Because of programming limitations, 1 CR 10 was capable of monitoring and controlling a maximum of 5 chambers if target temperatures were required to change as often as every hour. The CR10 communicated with a relay driver that controlled mechanical relays which provided 110 volts $\mathrm{AC}$ to the individual heaters, lights, and compressors for each chamber (Fig. 1).

Figure 2 provides a schematic of the control logic for the chambers. The CR10 datalogger was programmed to scan memory 


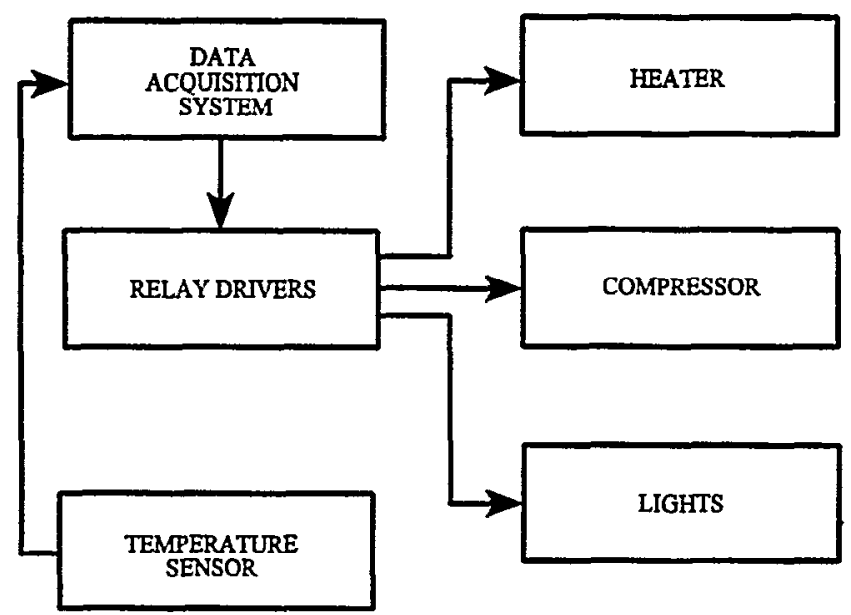

Fig. 1. System schematic outlining temperature monitoring and control features.

storage locations that contained user-defined target temperatures for every hour in a given day. A temperature deviation of more than $0.5^{\circ} \mathrm{C}$ from the target temperature stimulated an appropriate heating or cooling response within a given chamber.

Chamber temperatures were measured with centrally located, type $T$ thermocouples every 10 seconds. The time, date and 15min average temperature was recorded by a solid-state storage module. Every 10 seconds, the datalogger insured that the system did not exceed predetermined temperature safety limits. Individual chambers would have shut down automatically if chamber temperature rose above $46^{\circ} \mathrm{C}$ or dropped below $-1^{\circ} \mathrm{C}$. Chamber shutdown consisted of deactivation of the lights, heaters and compressor until the user reset the program specific to the disabled chamber. The datalogger also checked the battery every 10 seconds and if the voltage fell below 11.0 volts, all 5 chambers would automatically shut down. An additional safety feature for over-temperature protection was the utilization of a $63^{\circ} \mathrm{C}$ thermal breaker in the light and heater circuit for each chamber.

The datalogger was programmed to evaluate the status of chamber components every $3 \mathrm{~min}$. The compressor would automatically activate when the chamber temperature exceeded the upper-temperature threshold for a given time period. The compressor would turn off and the heaters activate when the temperature dropped below the lower-temperature threshold for a given time period. The heaters were prevented from activating during periods when the lights were on. The heat output of the lights and fan motors was generally sufficient to keep up with any required temperature rise when the compressor was deactivated. Prevention of simultaneous lighting and heating reduced the chance of a control failure that would cause the chamber to overheat. This redundant safety feature could be bypassed if a faster temperature response was required.

\section{Laboratory Simulation of Field Temperature}

The field temperature regime presented in this paper was measured at the Bureau of Land Management Orchard Field Test Site in southeastern Ada County, Ida. Eight thermocouples were distributed in the soil at 1-cm depth among seedling emergence plots at the experimental site. The experimental plots were burned in

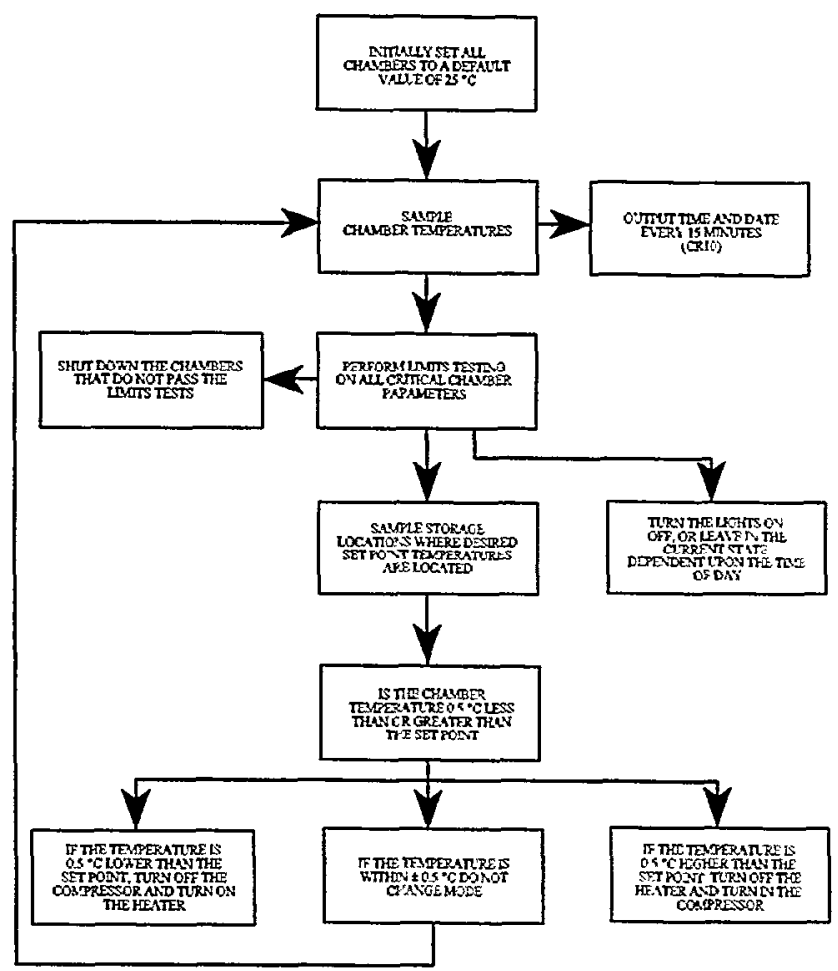

Fig. 2. Flow chart showing programming logic for temperature control system.

the preceding fall and were free of vegetation during the measurement period. Soil temperatures were monitored continuously and the data recorded every hour by a CR10 datalogger. Daily data from the field site were transmitted by radio to a computeractivated transceiver in the laboratory every morning at 4:00 am. These data were automatically stored in a computer database. A computer program was written to extract hourly-mean tempera-

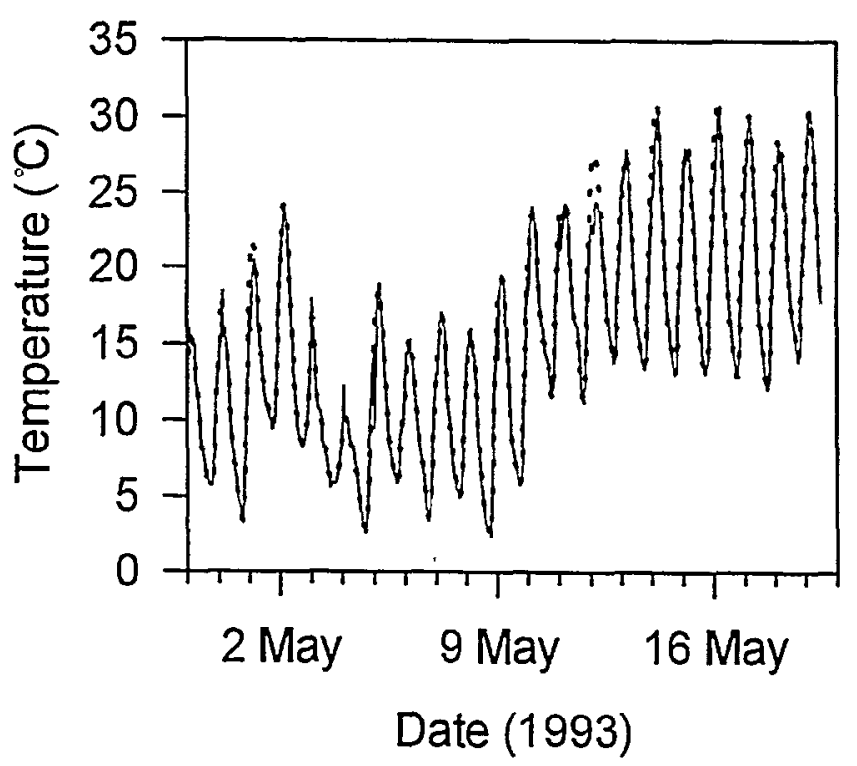

Fig. 3. Conformance between monitored chamber temperature (solid line) and measured field temperature at $1 \mathrm{~cm}$ depth (broken line) for a 3 week period in May, 1993. 


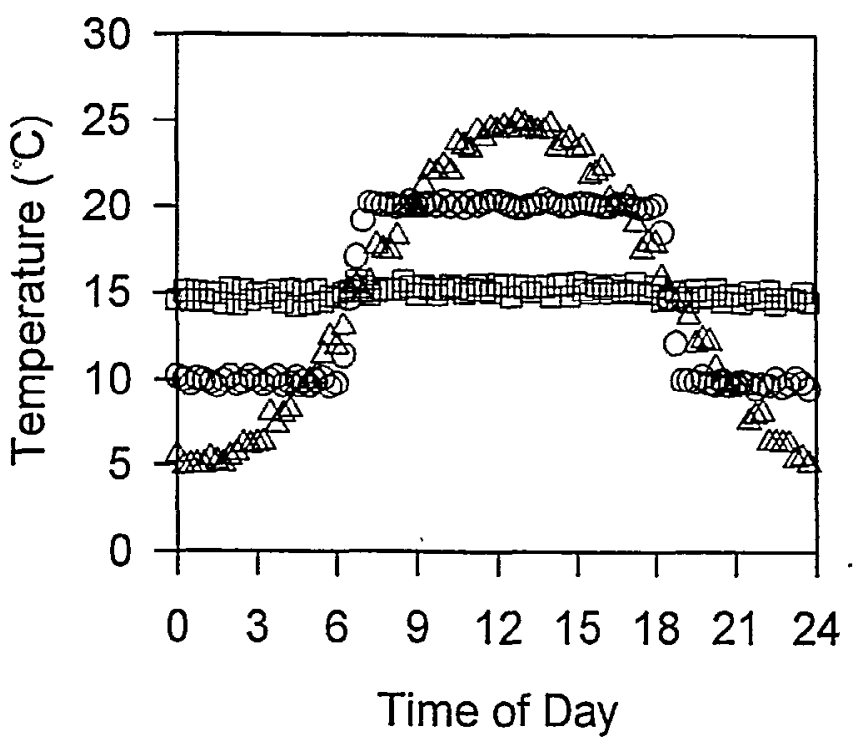

Fig. 4. Chamber temperatures measured every $15 \mathrm{~min}$ for constant (a), alternating (o) and sine-wave ( $\Delta$ ) temperature patterns for 3 chambers with a mean temperature of approximately $15^{\circ} \mathrm{C}$.

ture data from the database. This program created a batch file to run communications software between the computer and the datalogger control system. Implementation of the batch file automatically reset the chamber temperature regime for the following 24 hour period. The programming procedure needed to be done during the same 1-hour period, every day of the temperature simulation. Chambers simulating field-temperature regimes were programmed with a 3-day lag time so that laboratory germination and field emergence plots could be monitored on alternate days, and to account for occasional disruption of the radio telemetry on any given day. The computer system could be bypassed, and the chambers programmed manually, through a CR10 keyboard attached directly to the datalogger. Manual programming was relatively efficient only for programming long-term constant-temperature regimes.

\section{Results and Discussion}

Young and Evans (1982) compiled the germination profiles of a large number of cool-season range grasses for constant and alternating-constant temperature response. Alternating-constant day and night temperatures do not adequately simulate diurnal temperature patterns or short- and long-term changes in mean daily temperature. Figure 3 shows the degree of conformance between field and laboratory temperature regimes that was achieved during a 3-week period in the spring of 1993. The field temperature simulations were very accurate for temperatures below laboratory ambient. At higher-than-ambient temperatures, the germinator chambers lagged slightly behind rising field temperatures during the warmest part of the day. Some germinator chambers could not maintain temperatures as low as $5^{\circ} \mathrm{C}$ during the day with a full incandescent light load. The experiment that generated the data in Fig. 3 was conducted at full fluorescent and half-incandescent lighting to achieve adequate temperature control early in the spring when night temperatures routinely dipped below $5^{\circ} \mathrm{C}$. Switching to a full incandescent light period during the middle of May would have reduced the discrepancy between laboratory and field temperatures later in the spring.

Constant, alternating-constant, and sine-wave temperature patterns were also generated at our laboratory during the course of several germination studies using this system. Figure 4 demonstrates the relative precision of temperature control for 3 laboratory scenarios that all have a mean temperature of approximately $15^{\circ} \mathrm{C}$, about the same as the mean temperature for the 3 week period shown in Fig. 3.

The germination control system described here allows for nearreal-time simulation of field temperature patterns, consistency among treatment environments and a practical management system for simultaneous evaluation of several replicated temperature regimes. Future research utilizing variable temperature control will allow us to develop a stronger linkage between laboratory germination and field emergence patterns.

\section{Literature Cited}

Hardegree, S.P. and W.E. Emmerich. 1992. Effect of matric-priming duration and priming water potential on germination of four grasses. J. Exp. Bot. 43:233-238.

Hurlbert, S.H. 1984. Pseudoreplication and the design of ecological field experiments. Ecol. Monogr. 54:187-211.

Pierson, F.B. and J.R. Wight. 1991. Variability of near-surface soil temperature on sagebrush rangelands. J. Range Manage. 44:491-496.

Wester, D.B. 1991. A summary of range plant seed germination research. ICASALS Pub. no. 91-2. Texas Tech Univ., Lubbock, Tex.

Young, J.A. and R.A. Evans. 1982. Temperature profiles for germination of cool season range grasses. USDA, ARS, ARR-W-27, Oakland, Calif. 